\title{
Signaling in political budget cycles. How far are you willing to go? ${ }^{\infty}$
}

\author{
J orge Miguel Streby
}

November 2001

\begin{abstract}
This paper analyzes how heterogeneity in two dimensions, competency and character, axects political budget cycles. Competency is the ec ciency in running the government. Character is the degree of opportunism. In this expanded space, previous results in the literature on the separating nature of the signaling equilibrium hold if heterogeneity in opportunism is low. With high heterogeneity in opportunism, no separating equilibrium exists. Rather, the equilibrium is partially pool ing: only extreme types can be distinguished.
\end{abstract}

ॠ thank Delia Ferreira Rubio, J exry Frieden, G eorge M cCandless, J uan Pablo Nicolini, Fed erico W ein schelbaum, and, very especially, Ernesto Stein for their stimulating ideas and insights. I appreciate the comments by participants at a seminar at UTDT, and at the meetings of the AAEP in Rosario, the LACEA in R io de Janeiro, and the Econometric Society in Punta Chica, B uenos Aires.

y orge M. Streb, Universidad del CE M A, A v. Córdoba 374, 1054 Buenos Aires, A rgentina; e-mail jms@cema.edu.ar; tel.54-11-4314-2269. 
Key words: rational political budget cycles, two-dimensional asymmetric information, signaling, discretion, adverse selection.

JEL: D7, E6

The literature on opportunistic political cycles has est ablished that, with rational voters, cycles can signal the competency of the incumbent. The work-horse models by Rogox (1990) and Lohmann (1998) show there is a separating equilibrium where competent incumbents stand out from the rest. This opportunistic political cycle literature assumes that rational voters can ..gure out just how far an incumbent is willing to go to get reelected.

The problem with the existing results is the implicit assumption that opportunism is common knowledge. In fact, opportunism is part of an individual's utility function. Since utility functions are not observable, opportunism has to be inferred from the actions of the incumbent, just like competence. This is the theoretical motivation to explore the consequences of asymmet ric information on opportunism.

A symmetric information on opportunism can be relevant only if political candidates are suф ciently heterogeneous in this dimension. The fact that politicians dixer in opportunism is recognized by Tufte (1978) in his classic study of political control of the economy. He draws a clear-cut contrast between Ford, who was not willing to take the short view before elections, and $\mathrm{N}$ ixon, who was willing to exploit pre-electoral engineering to its utmost.

That individuals can dixer both in competency and in character is also at the heart of the Akerlof (1970) lemons model. The problem with lemons 
arises not only because there are dix erent quality cars, but also because there are dishonest sellers who are willing to misstate the quality of a used car. The issue of lemons literally pertains to politics: in a political campaign, voters were asked if they would buy a used car from one of the candidates pictured running for oф ce.

In relation to opportunistic cycles, Alesina, Roubini, and Cohen (1997) can empirically reject systematic opportunistic cycles before elections implied by Nordhaus (1975). However, they cannot reject the implications of the seminal R ogow (1990) paper, namely that political cycles occur frequently, though not always, before elections. Alesina et al. (1997) object the Rogow approach on other grounds, namely that his result that only competent incumbents distort economic policy is troublesome and unrealistic. This paper builds on Rogox to show that this result is not inherent to the opportunistic approach.

This paper proposes an extended framework for rational political budget cycle (RPBC) models wherethe consequences of two-dimensional asymmet ric information can be analyzed. When opport unism is not common knowledge, incompetent incumbents can also distort economic policy. This paper is related to Stein and Streb (1999), who model the electoral manipulation of exchange rates in a signaling game that is a special case of the present framework.

Section I spells out the economy and the polity, focusing on the potential trade ox between visible and less visible budget items. Section II considers 
the R PBC model under asymmetric information on opportunism and competency, and looks at the welfare implications. Section III looks at some conceptual issues surrounding the model. Section IV presents the conclusions.

\section{Economy and Polity}

This Section describes the utility functions of voters and politicians, the government budget constraints and the el ectoral institutions. The model follows the Rogow (1990) distinction between public consumption and investment goods, that gives rise to more and less visible budget items, as the key device to model budget cycles around elections.

\section{A. Utility Functions}

The economy is reduced to the net provision of public goods. There are a large number of representative consumers, who are also voters. V isible budget items, $g_{t}$, are observed by voters contemporaneously, and less visible budget items, ${ }^{\circ}+1$, are observed with a one-period lag. The variables $g_{t}$ and ${ }_{\mathrm{t}+1}$ refer to the provision of public goods net of taxes.

The representative individual derives utility from the consumption of $g_{t}$ and ${ }^{\circ}$. Utility $\mathrm{U}$ is separable over time, and within each period it is separable over both goods: 


$$
U=X_{t=0}^{\top} \frac{u\left(g_{t} ;{ }_{t+1}\right)}{\left(1+t^{t}\right.} ; u\left(g_{t} ;{ }_{t+1}\right)=w\left(g_{t}\right)+\frac{v\left({ }^{\circ} t+1\right)}{1+ \pm} ;
$$

where v,w are strictly concave, w0>0,v0>0, and va0)! 1 (to assure an interior solution in what follows).

The incumbent is selected from among the population. An incumbent has preferences similar to voters. It enjoys a satisfaction $K, 0$ from being in o $c$ ce, the ego-rent or kick from being the leader. This will be the source of opportunistic behavior. Let $\mu_{\mathrm{t}}=1$ when the individual is incumbent, and 0 when not. $Z$ gives the incumbent's lifetime utility:

$$
Z=U+{ }_{t=0}^{X} \frac{\mu_{t} K}{(1+ \pm)^{t}}
$$

The literature implicitly assumes that the kick $\mathrm{K}$ is common knowledge. Instead, we explore the consequences of opportunism being a random variable $\mathbb{R}$. We work with polar types. The incumbent can either be nonopportunistic, with realization $\mathrm{K}=0$, or highly opportunistic, with realization $\mathrm{K}=\overline{\mathrm{K}}>0$, where $\overline{\mathrm{K}}$ will be characterized in Section II. The priors are that with probability s the incumbent is highly opportunistic, while with probability 1 i s it is non-opportunistic. A non-opportunistic incumbent behaves as a benevolent social planner, while an opportunistic incumbent is willing to distort policy on behalf of its personal interests. The distance between both types, given by $d^{\prime} \bar{K}$ i $0=\bar{K}$, determines the degre of heterogeneity. 


\section{B. B udget Constraints}

The government is subject to the following per-period budget constraint, where " $t$ denotes actual competency:

$$
g_{t}+\frac{{ }^{\circ}+1}{1+ \pm}={ }_{t}
$$

A more competent government can provide more of both $g_{t}$ and ${ }^{\circ}{ }_{t+1}$. For a given " $t$, a trade-o between $g_{t}$ and ${ }^{\circ}{ }_{t+1}$ exists: larger expenditures on visible public goods, and lower visible taxes, can be achieved at the cost of hikes in taxes, and reduction in expenditures, that only become visible after elections. This trade-ox reł ects budget cycles around elections, by which a larger pre-electoral budget de..cit requires a larger post-electoral surplus.

We assume that the actual competency of the incumbent follows an MA (1) process, as in Rogox and Sibert (1988), according to the realizations of current and lagged competency shocks:

$$
{ }_{t}="+\mathbb{R}_{t}+\mathbb{R}_{\mathrm{i} 1}
$$

The priors voters have about random variable $e_{\text {a }}$ are that with probability $r$ the shock is positive ( $\Theta_{t}={ }^{\circ}$, competent), and with probability 1 i $r$ the

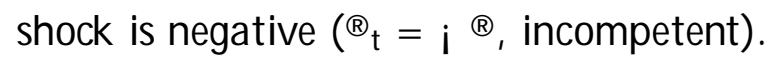

Consequently, incumbents dixer in two dimensions: competency and opportunism. Competency shocks $e_{t}$ are assumed to be independently distributed from the kick $\mathbb{R}$. 


\section{Voting Behavior}

Let the total utility of a voter $i$ be given by $U_{t}+q_{t ; i}$, where $q_{t ; i}$ is the personal appeal of a candidate to voter $i$. We assume that $q_{t ; i}$ is the realization of a random shock ; which is white noise and has an uniform distribution over the interval $[\mathrm{i} q ; \mathrm{q}]$, and that $\mathrm{q}_{\mathrm{t} ; \mathrm{i}}$ is independent across individuals.

In regard to the institutional setup, we assume an incumbent's term in of ce lasts two periods. Furthermore, we will restrict the analysis in this paper to the case wherethe incumbent has a two-term limit, as in present U.S. constitutional practice, so an incumbent can at most be reelected once (this allows to abstract from reputational consequences of opportunistic behavior).

\section{Rational Political Budget Cycles}

Rogox (1990) and Lohmann (1998) present models of R PBC that dixer in their timing. In Rogox (1990), there is asymmetric information because incumbents decide policy after they observe competency. Since competency is known ex-ante, only competent incumbents engage in budget cycles, while incompetent incumbents do not. In contrast, Lohmann (1998) develops a model with symmetric information, where incumbents decide policy before they observe competency. All incumbents engage in monetary cycles before elections, but, ex-post, competent incumbents are able to go farther than incompetent ones. Persson and Tabellini (1999) treat the dixerence between symmetric information on competency in Lohmann (1998), and asymmet- 
ric information on competency in R ogox (1990), as the dixerence between a moral hazard problem and an adverse selection problem. O nce heterogeneity in opportunism is introduced, the dixerence between both setups fades. A dverse selection is present from the start.

This Section reviews the Rogox (1990) results as a benchmark. The signaling model is then extended from the one-dimensional asymmetric information setup, where opportunism is common knowledge, to a two-dimensional asymmetric information setup. We show no separating equilibrium exists when the degree of heterogeneity $d=\bar{K}$ is suф ciently large.

The timing of the game each period is as follows. The incumbent observes the competency shock " ${ }_{t}$ before it decides ${ }^{\circ}{ }_{t+1}$ and $g_{t}$. Visible $g_{t}$ is then observed by all individuals. This sequence implies that in an election period incumbents have an informational edge over voters in relation to their competency, as depicted in Figure 1.

<please insert Figure 1 about here>

The MA (1) process in equation (4) implies that shocks in ox-election periods do not axect performance after elections, so only competency shocks in election periods matter for forward-looking voters. Since competency shocks in ox-election periods do not axect voting decisions in election periods, the incumbent's decision problem is decomposable into on- and ox-election periods. In ox-election periods, budget decisions are not axected by electoral considerations. 


\section{A. Ox-election Periods}

Consider an ox-election period t. No signaling is involved because the cur rent competency shock only axects performance before el ections, so this information is not relevant for the decisions of forward-looking voters. Since the kick from being in oф ce is not at stake, an incumbent will pick $g_{t}$ to maximize (1), subject to budget constraint (3). The FOC is

$$
\left.w\left(g_{t}\right)=v Q^{\circ}{ }_{t+1}\right)
$$

This condition determines optimal $g_{t}^{a}\left(\AA_{t_{i}} ; \AA_{t}\right)$ and $\underset{t+1}{\circ a}\left(\bigotimes_{t_{1}} ; \AA_{t}\right)$. M ore competent incumbents deliver more visible and invisible public goods, and charge lower visible and invisible taxes. This determines a level of indirect utility

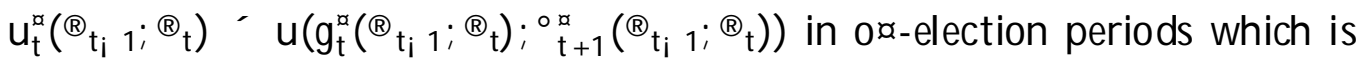
higher with competent incumb ents that have $\AA_{t}={ }_{\text {. }}$.

More relevant for electoral decisions will be the fact that indirect utility $u_{t}^{\mathrm{a}}\left(\AA_{\mathrm{ti}_{1}} ; \AA_{\mathrm{t}}\right)$ is higher with $\AA_{\mathrm{t}_{1} 1}={ }^{\circledR}$ than with $\AA_{\mathrm{t}_{1} 1}=\mathrm{i}{ }^{\circledR}$. This will imply that voters are more likely to reelect incumbents that have high competence in election periods, as we now show.

\section{B. Election Periods}

Maximizing voters comparethe incumbent with an opposition candidate chosen at random from the population. Voters base their decision on the perceived competency of the candidates and on the appeals shocks $q_{\mathrm{t} ; \mathrm{i}}$ and $\mathrm{q}_{\mathrm{t} ; \mathrm{i}}^{\mathrm{o}}$ 
(superscript o denotes the opposition candidate; no superscript is used for incumbent). This implies that there is probabilistic voting.

A $n$ election will be determined by the median voter. An incumbent will be reelected if the expected indirect utility of median voter $m$ in period $t+1$, conditional on information available in $\mathrm{t}$, is higher with the incumbent than with the opposition candidate: ${ }^{1}$

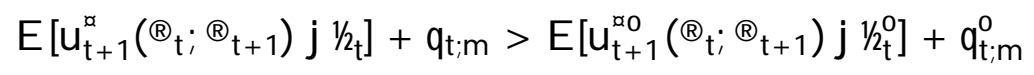

The information in (6) that conditions expectations refers to information on visible expenditure, that can be used to eval uate the probability $1 / 2$ that the incumbent is competent. In the case of the opposition candidate, expected competency is exogenously given at $1 / p=r .^{2}$ There is no incumbency bias: rule (6) followed by forward looking voters implies that if the incumbent is perceived to be competent with the same probability as opposition candidate, the incumbent's probability of reel ection will be $\frac{1}{2}$.

Since indirect utility $u_{t+1}^{a}\left(\bigotimes_{t} ; \bigotimes_{t+1}\right)$ after elections is increasing in current competency $\AA_{\text {, }}$, voting rule (6) implies that voters who maximize expected

\footnotetext{
${ }^{1}$ The MA (1) structure in (4) restricts the future horizon to one period, since electoral decisions can only axect the expected value of out comes in the next period. T he expressions for expected indirect utility in (6) take into account the probability $1 / 2$ the candidate is

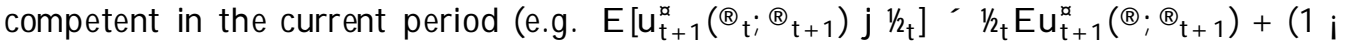
$\left.1 / 2) E u_{t+1}^{a}\left(i \mathbb{R}_{,} \mathbb{R}_{+1}\right)\right)$, and the probability $r$ candidates will be competent next period (e.g.

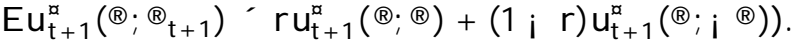

${ }^{2}$ If none of the candidates had a track record, the election would solely hinge on their personal appeal. The winning candidate would be determined by whether $q_{t ; m} i \quad q_{; m}^{p}$ is positive or negative for the median voter.
} 
utility are more likely to reelect an incumbent when the probability $1 / 2$ it is competent $\left(\mathbb{R}_{\mathrm{t}}={ }^{\circledR}\right)$ is higher.

\section{One-dimensional A symmetric Information}

We present a stripped down version of the Rogox (1990) model. The model implicitly assumes that the opportunism of incumbents is observable.

Rogox and Sibert (1988) showed that political budget cycles can signal competency to rational forward looking voters. Rogox (1990) reformulated the signaling game in a fully optimizing framework with two types of competency, high and low. The equilibrium will be separating: incumbents with high competency choose high expenditure and low taxes before elections, while incompetent incumbents do not.

Say $g_{t}^{s}$ is the level of visible public goods that a competent incumbent picks in a separating equilibrium, while an incompetent incumbent picks the lower level $g_{t}^{a} ' g_{t}^{\mathfrak{a}}\left(\AA_{i_{i}} ; i_{i}{ }^{\circledR}\right)$. Consequently, voter's beliefs will be given by:

$$
\begin{aligned}
& g_{t}=g_{t}^{s} \quad ＼quad 1 / p=1 \\
& \left.g_{t}=g_{t}^{a}\left(\AA_{t} ; ; ; \AA\right) \quad\right) \quad 1 / 2=0
\end{aligned}
$$

In equilibrium, voters will infer that an incumbent who delivers $g_{t}^{s}$ is competent. For other, out-of equilibrium, values of visible expenditure, we assume the lower threshold of each interval de..nes expected competency. Thus, while the separating signal g leads to a reputation of competency 
$1 / q=1$, not signaling with at least that level of visible budget items leads to lose any such reputation, so $1 / z=0$.

For this to actually be a Perfect Bayesian Equilibrium, competent and incompetent incumbents must be willing to pick these signals. If the incumbent is incompetent, its expected utility from picking the separating signal $g_{t}^{S}$ must not be larger than its expected utility from picking $g_{t}^{\mathfrak{a}}\left(\Theta_{t_{i}} 1 ; i \AA\right.$

$$
E\left[Z^{S} j \otimes_{t}=i \circledast\right] \quad E\left[Z^{\circledR} j \AA_{t}=i \circledast\right]
$$

The dixerence in expected utility between the LHS and the RHS of equation (8) can be expressed as the temptation to signal of an incompetent incumbent. $M$ ore generally, for an incumbent of type $\mathbb{R}_{t}$, the temptation $\mathrm{T}\left(\mathrm{g}_{\mathrm{t}}^{\mathrm{S}} ; \mathrm{g}_{\mathrm{t}}^{\mathrm{d}}\left(\Theta_{\mathrm{t}_{1}} ; \AA_{\mathrm{t}}\right) \mathrm{j} \AA_{\mathrm{t}}\right)$ can be expressed, by algebraic manipulation, as the dixerence between the expected future bene.ts - due to the increased probability of enjoying the perks of being in of ce two periods more - and the expected welfare costs - due to the distortion produced by the budget cycle - , i.e.:

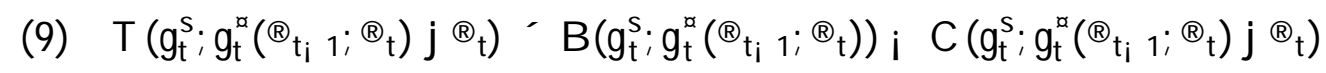
where

$$
B\left(g_{t}^{S} ; g_{t}^{a}\left(\Theta_{t_{i} 1} ; \Theta_{t}\right)\right)^{\prime}\left[p\left(g_{t}^{S}\right) ; p\left(g_{t}^{\mathbb{a}}\left(\Theta_{t i 1} ; \Theta_{t}\right)\right)\right]_{i=1}^{X^{2}} \frac{K}{(1+ \pm)^{i}}
$$


and

(11)

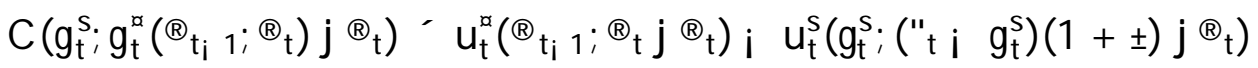

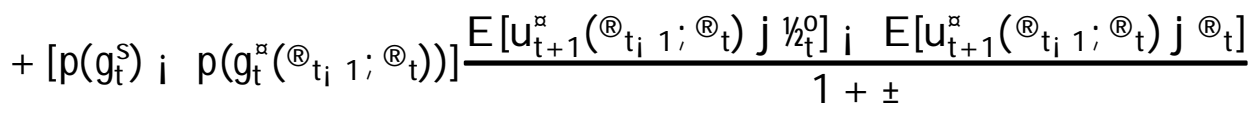

The expected welfare costs comprise a current cyclical exect and a future weal th exect. The wealth exect is due to the fact that while an opposition candidate has a probability $1 / 2=r$ of being competent in $t+1$, an incumbent knows its competency ${ }_{\mathbb{C}}$ will be either be high or low for sure. The wealth exect is an added cost of signaling for an incompetent candidate, and a bene.t for a competent candidate.

In a separating equilibrium, condition (8) can be expressed as the condition that an incompetent must not face a positive temptation to deviate from $g_{t}^{a}\left(\Theta_{t_{i}} ; ; @\right): 3$

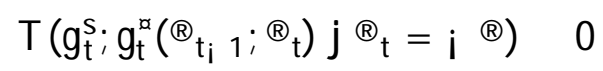

For cycles to exist, the separating signal $g_{t}^{s}$ has to belarger than $g_{t}^{\mathrm{a}}\left(\AA_{t_{i}} ;\right.$; $\left.\circledR\right)$, because otherwise a competent can signal its type choosing its ..rst best. De-

\footnotetext{
${ }^{3}$ We assume that when the bene..t is equal to the cost of signaling, i.e.

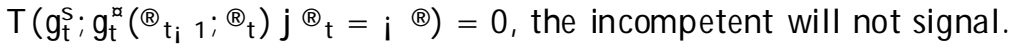




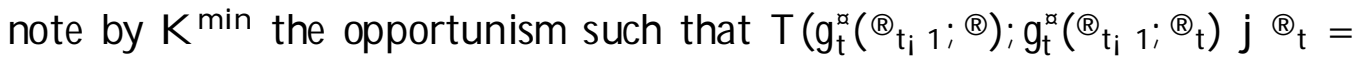
$\left.\mathrm{i}{ }^{\circledR}\right)=0$. We characterize opportunism as high when the following holds:

$$
\bar{K}>K^{\min }
$$

Condition (13) assures that a competent incumbent has to produce a budget cycle to dixerentiate itself. If opportunism were smaller than $\mathrm{K}^{\mathrm{min}}$, the equilibrium would still be a separating, but there would be no budget cycle. In that instance, the competent would be able to signal its type by picking $g_{t}^{\mathrm{d}}\left(\AA_{\mathrm{i}_{1}} ;{ }^{\circledR}\right)$, without distorting current expenditure. Thus,

Proposition 1 Assume information on competency is asymmetric and information on opportunism symmetric. The equilibrium is separating. If opportunism is low, there is no political budget cycle. If opportunism is high, competent incumbents engage in a political budget cycle.

This is a restatement of Propositions 1 and 2 in R ogoo (1990).

No pooling equilibrium survives the application of equilibrium dominance arguments. To see this, say that a pooling equilibrium exists and that it is given for example by the level $g_{t}^{a}\left(\AA_{i_{1}}\right.$; $\left.\circledR^{\circledR}\right)$ that is optimal for a competent incumbent. In a pooling equilibrium, $1 / 2=r$, so by voting rule (6) the probability of reelection $p\left(g_{t}^{\mathbb{a}}\left(\Theta_{\mathrm{t}_{1}} ;{ }^{\circledR}\right)\right)=\frac{1}{2}$.

To consider deviations from the pooling equilibrium, it is convenient to derive the indixerence curves of each type of incumbent. Dixerentiating 
condition $T\left(g_{t}^{\alpha}\left(\Theta_{t_{i}} ; \AA_{t}\right) ; q_{t}^{\alpha} j \Theta_{t}\right)=0$ with respect to $g_{t}$, one can ..nd the pairs $\left(g_{t} ; p\left(g_{t}\right)\right)$ that leave an incumbent of type $\mathbb{B}_{t}$ indixerent:

$$
p\left(g_{t}\right)=\frac{\left.\left.v Q_{t+1}^{\circ}\right) i w Q g_{t}\right)}{\frac{\left.E\left[u_{t+1} j^{Q}\right]_{i}\left[u_{t+1}^{\circ}\right]^{1 / 2}\right]}{1+ \pm}+\frac{(2+ \pm K K}{(1+ \pm)^{2}}}
$$

If $K$ were so small for the denominator of (14) to be negative, an incompetent incumbent would not be willing to mimic $g_{t}^{a}\left({ }_{t_{i}} ;\right.$; $\left.{ }^{\circledR}\right)$ in the ..rst place because the bene..t of being reelected to o ce would not even compensate the negative wealth exect. Thus, the denominator must be positive for a pooling equilibrium to exist (condition (13) is su cient for the denominator to be positive). By FOC (5), the numerator is zero at $g_{t}^{a}\left(\Theta_{t_{i}} ; \AA_{t}\right)$. Due to the concavity of the utility functions $v$ and $w$, indixerence curves are convex. The convexity of the indixerence curves means that they reach a minimum at $g_{t}^{a}\left(\AA_{t_{i} 1} ; i ~(\circledR)\right.$ for an incompetent, and at $g_{t}^{a}\left(\AA_{t_{i}} ;{ }^{\circledR}\right)$ for a competent. The indixerence curves through $g_{t}^{\circledR}\left(\AA_{t_{i}} ;\right.$; $)$ are depicted in Figure 2 .

$<$ please insert Figure 2 about here>

From Figure 2, one can see that the indixerence curves of an incompetent incumbent to the right of $g_{t}^{a}\left(\Theta_{i_{1}} ;{ }^{\circledR}\right)$ will besteeper than the indixerence curves of a competent incumbent. ${ }^{4}$ Therefore, the deviation that would leave an incompetent incumbent indixerent between the pooling equilibrium and establishing a reputation of competency $1 / z=1$ would make the competent

\footnotetext{
${ }^{4}$ For competent incumbents, the denominator in (14) is larger because of positive wealth exect in the future, and the numerator is smaller because for any given $g_{t}$ they can provide more ${ }_{t+1}^{\circ}$, so $\left.v q^{\circ}{ }_{t+1}\right) i w q g$ ) will be a smaller positive number.
} 
better ox. Only the competent is willing to deviate from the pooling equilibrium, so applying the Cho-K reps criterion voters will infer the incumbent is competent if that $g_{t}$, or more, is observed. A pplying this same argument to other possible equilibrium points, one can show no pooling equilibrium survives. $^{5}$

\section{Two-dimensional A symmetric Information}

We now extend the setup to asymmetric information on both competency and opportunism. Instead of two types of incumbents, there are now four types: opportunistic and non-opportunistic, who can be either competent or incompetent. We will show that if heterogeneity is low, there is a separating equilibrium, as in R ogox (1990). If heterogeneity is high, the equilibrium is instead semi-separating.

We posit the following signals in the Perfect Bayesian Equilibrium:

$$
\begin{aligned}
& \left.g_{t}=g_{t}^{s}\right) \quad 1 / 2=1 \\
& \left.g_{t}=g_{t}^{a}\left(\circledast_{t_{i}} ; \circledR\right)\right) \quad 1 / 2=\frac{(1 ; s) r}{(1 ; s) r+s(1 ; r)} \\
& \left.g_{t}=g_{t}^{a}\left(\AA_{t i} ; ; \circledR\right)\right) \quad 1 / 2=0
\end{aligned}
$$

\footnotetext{
${ }^{5}$ One can replicate this analysis for the model in chapter 5 of Persson and Tabellini (1990) and chapter 2 of Alesina, Roubini, and Cohen (1997). When a separating equilibrium exists, the pooling equilibria can be eliminated through the application of the intuitive criterion. This result can be demonstrated using the space of signals and probability of reelection to depict the signaling game (proof omitted). This implies that the rational business cycle model in Persson and Tabellini (1990), as well as in Alesina et al. (1997), belong to exactly the same class as Rogox (1990).
} 
The variable, in (15) stands for the probability that an incompetent, opportunistic, incumbent is willing to mimic $g_{t}^{a}\left(\AA_{t i} ;{ }^{\circledR}\right)$. The value of $g_{t}^{s}$ will be de..ned below. 0 ut-of-equilibrium values of $g_{t}$ are assumed to lead to the same reputation of competency as the lowest value in each interval of (15).

To establish that this is indeed the equilibrium, we have to make sure that no type of incumbent wants to deviate from the proposed solution. The tempt ation to signal depends on two factors, competency $\mathbb{R}_{t}$ and opportunism K :

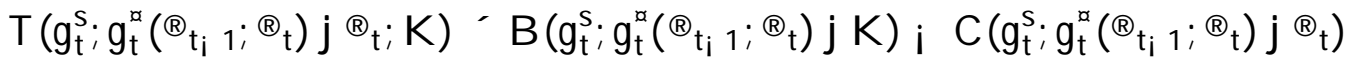

The cost $C\left(g_{t}^{5} ; g_{t}^{a}\left(\Theta_{t_{1}} ; \AA_{t}\right) j \AA_{t}\right)$ is as de..ned in (11) above. The bene.tt of reelection $B\left(g_{t}^{S} ; g_{t}^{d}\left(\Theta_{i} 1 ; \AA_{t}\right) j K\right)$ is as in (10) for opportunistic incumbents with $\mathrm{K}=\overline{\mathrm{K}}$, but zero for non-opportunistic incumbents with $\mathrm{K}=0$.

The problem under two-dimensional asymmetric information is that, if heterogeneity in opportunism is su $₫$ ciently high, an incompetent incumbent may be willing to go farther than a competent incumbent to produce a political budget cycle.

To establish this, we..rst introduce some notation. Let $g_{t}^{\text {ext }}$ denote the visible budget items for which the temptation to signal of a non-opportunistic, competent, incumbent becomes zero (and beyond which extreme the temptation becomes negative), $T\left(g_{t}^{\text {ext }} ; g_{t}^{a}\left(\Theta_{t_{i}} ; \AA_{t}\right) j{ }_{t}={ }_{B}, K=0\right)=0$. Furthermore, let $K$ ext be the level of opportunism for which the temptation of 
an incompetent, opportunistic incumbent to pick $g_{t}^{\text {ext }}$ and gain a reputation of competency $1 / 2=1$ is exactly zero, $T\left(g_{t}^{\text {ext }} ; g_{t}^{a}\left(\AA_{t} 1 ; \AA_{t}\right) j \AA_{t}=i{ }_{i}, K=\right.$ $\left.K^{e x t}\right)=0$.

The following condition will imply that heterogeneity $d=\bar{K}$ is high:

$$
\bar{K}>K^{e x t}
$$

For high heterogeneity $\bar{K}>K$ ext, we now show that only a partially pooling equilibrium exists. There is a simple intuition behind the solution: a non-opportunistic incumbent is not willing to distort economic policy for electoral gain. In particular, a non-opportunistic incumbent that is competent acts to maximize social welfare, so it is only willing to signal as far as the cyclical distortion is smaller than the positive wealth exect.

Let the signal $g_{t}^{S}$ in (15) be de. ned by the condition that $T\left(g_{t}^{S} ; g_{t}^{\mathrm{a}}\left(\AA_{t_{i}} ; \AA_{t}\right) j\right.$ $\left.\mathrm{i}{ }^{\circledR}, \bar{K}\right)=0$. Consider ..rst the non-opportunistic types. A competent incumbent will prefer $g_{t}^{\mathrm{a}}\left(\AA_{\mathrm{i}_{1}} ;{ }^{\circledR}\right)$ to $g_{t}^{\mathrm{s}}$ because its temptation to signal is negative at $g_{t}^{s}>g_{t}^{\text {ext }}$. On the other hand, an incumbent who is incompetent never deviates from $g_{t}^{\mathfrak{a}}\left(\Theta_{i} 1 ; i{ }^{\circledR}\right)$.

Consider now opportunistic types. A competent incumbent will be willing to signal $g_{t}^{s}$, while an incompetent will by construction prefer not to signal. It remains to show what an incompetent, opportunistic, incumbent will actually do. Given assumption (17), one can always assure that there is a probability . > 0 such that an incompetent, opportunistic, incumbent is willing to mimic 
$g_{t}^{a}\left(\circledR_{i_{i}} ;{ }^{\circledR}\right){ }^{6}$ Moreover, for a large enough $\bar{K}$ one can assure the equilibrium will be in pure strategies $(,=1)$.

For low heterogeneity $\bar{K} \quad K$ ext, a separating equilibrium exists. At the separating signal gt where an incompetent, opportunistic, incumbent is just

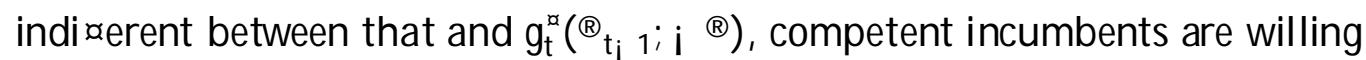
to send separating signal. Behavior in (15) collapses to signals in (7), where competent incumbents pick $g_{t}^{5}, g_{t}^{a}\left(\Theta_{i} 1 ;{ }^{\circledR}\right) .{ }^{7}$ Consequently,

Proposition 2 Assume information on competency and on opportunism is asymmetric. If heterogeneity in opportunism is low, a separating equilibrium exists. If heterogeneity is high, a separating equilibrium does not exist. The equilibrium is partially pooling, and opportunistic incumbents engage in a political budget cycle.

It is not problematic to justify that opportunism may be high, since the idea that the driving force of politicians is to win elections is a classic in political science (Schumpeter, 1942; Downs, 1957). What may be problematic is the idea that some incumbents are non-opportunistic. Nevertheless, the crucial point for the results in Proposition 2 is not that there be nonopportunistic incumbents, but rather that opportunism be suc ciently het-

\footnotetext{
${ }^{6} \mathrm{~T}$ he gain from signaling can be made arbitrarily close to $B\left(g_{t}^{5} ; g_{t}^{a}\left(\Theta_{t_{1}} ; \AA_{t}\right) j \bar{K}\right)$ if, is

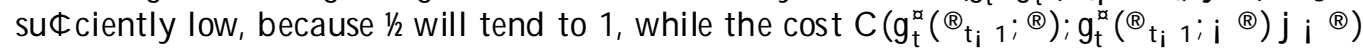
is lower than $C\left(g_{t}^{s} ; g_{t}^{a}\left(\AA_{i} i ; i ß\right) j ; \circledR\right)$.

${ }^{7}$ There is a separating equilibrium over the interval $\bar{K} 2\left[0 ; K^{e x t}\right]$, but over a certain interval of kicks to the left of $\mathrm{K}$ ext there is also a partially pooling equilibrium (details omitted). In this overlapping interval with multiple equilibria, the equilbrium will depend on the speci..cation of voter beliefs.
} 
erogeneous. $^{8}$

No pooling equilibrium is possible, because a non-opportunistic, incompetent, incumbent which will always choose $g_{t}^{a}\left(\AA_{t_{i}} ; i ß\right)$. By application of the Cho-K reps intuitive criterion, one can also rule out a partially pooling equilibrium where all other types of incumbents pick $g_{t}^{\circledR}\left(\circledast_{t_{i}}\right.$; $\left.{ }^{\circledR}\right)$. To establish this, F igure 3 depicts the indixerence curves that go through $g_{t}^{\mathfrak{a}}\left(\Re_{t_{i}} 1 ;{ }^{\circledR}\right)$. The indixerence curves are derived by dixerentiation of $T\left(g_{t}^{S} ; g_{t}^{a}\left(\AA_{t_{i}} ; \mathbb{R}_{t}\right) \mathrm{j} \AA_{t} ; K\right)$, for incumbents of types $(\AA ; 0),(\AA ; K)$, and $(i ® ;, K)$.

<please insert Figure 3 about here>

This partially pooling equilibrium would not resist the deviation by an opportunistic, competent incumbent, that would be willing to go beyond the signal gt that assures an opportunistic, incompetent incumbent a reputation of competency $1 / z=1$. Figure 3 shows the speci..c case where heterogeneity is high, so an opportunistic incumbent that is incompetent is willing to go farther to signal high competency than a non-opportunistic incumbent that is competent. This implies that no separating equilibrium exists either. Rather, there is a partially pooling equilibrium as characterized in Proposition 2.

\footnotetext{
${ }^{8} \mathrm{Unlike}$ this paper, where elections are probabilistic so the incumbent has an incentive to show it is competent for sure to increase as much as possible the probability of reelection, Stein and Streb (1999) have a model with two-dimensional asymmetric information where elections depend solely on the competency of the incumbent. Consequently, an incumbent only needs to establish that the probability it is competent is above aver age to be reel ect ed for sure. Given high heterogeneity in opportunism, Stein and Streb show that there is a semi-separating equilibrium where only incompetent, opportunistic incumbents distort policy, unlike this paper where all opportunistic incumbents distort policy. O ne can show that no separating equilibrium exists there when heterogeneity in opportunism is high for the reason given in Proposition 2: non-opportunistic, competent, incumbents will not be willing to go beyond the point where signaling costs are negative.
} 


\section{E. Welfare Exects of Cycles}

The welfare properties of budget cycles under two-dimensional asymmetric information can be characterized very neatly when one of the types is non-opportunistic. The sign of the welfare exects revolve around whether a separating equilibrium exists or not.

Proposition 3 Assume there is two dimensional asymmetric information. If there is a separating equilibrium, political budget cycles are welfare enhancing. If no separating equilibrium exists, political budget cycles are welfare reducing.

Pf. (i) A non-opportunistic, competent incumbent behaves like a benevolent social planner. This type signals in the range where signaling costs are negative (the positive future wealth exects for voters outweigh the current cyclical distortion), so cycles are welfare enhancing. This only holds for signals $g_{t}^{s}$ that correspond to $\bar{K} \quad K$ ext, the interval where a separating equilibrium exists. (ii) If $\bar{K}>K$ ext, no separating equilibrium exists. There is a partially pooling equilibrium where opportunistic incumbents distort the provision of visible public goods. In case they are competent, this distortion reduces welfare because signaling costs are positive (the positive wealth effect is smaller than the cyclical distortion). In case they are incompetent, signaling costs are positive because a negative wealth cost is added to the cyclical distortion. 
According to Proposition 3, cycles reduce welfare when no separating equilibrium exists. This is not equivalent to demonstrating that elections as such reduce welfare. Elections comprise both a policy bias and a selection exect (Lohmann, 1998). The current welfare loss that opportunistic incumbents produce through cycles is the policy bias, that is not present in ox-election periods. ${ }^{9}$ However, el ections have a selection exect, since they provide the option of changing the incumbent. In expected value, the electoral option has a positive wealth exect, since it allows to replace incumbents that are incompetent. ${ }^{10}$ The policy bias may be dominated by a selection exect, so the net welfare exect of elections is ambiguous (Lohmann, 1998, Proposition 4). Since the policy bias is increasing in the degree of heterogeneity in opportunism, the positive exect of el ections is less likely the higher the degree of heterogeneity.

\footnotetext{
${ }^{9}$ Opportunistic incumbents produce the bias, which amounts to an expected wel-

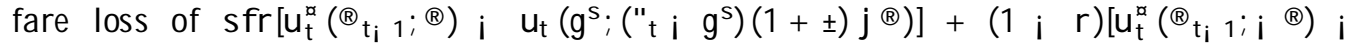

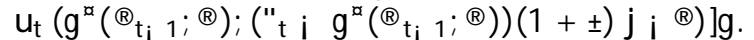

${ }^{10}$ Expected utility in period $t+1$ after elections in a partially pooling equilibrium depends on three possible scenarios: there is a separat ing signal $g_{t}^{s}$ that leads to probability $p(1)$ of reel ecting a competent in sr of the cases; there is an intermediate signal $g_{t}^{a}\left(\mathbb{Q}_{i}{ }_{1}\right.$; $\mathbb{R}$ ) that with probability $p(x)$, where $x=\frac{\left(1_{i} s\right) r}{\left(1_{i} s\right) r+s\left(1_{i} r\right)}$, leads to reelect a competent in $\left(1_{i} s\right) r$ of the cases, and an incompetent in $\mathrm{s}\left(1_{i} r\right)$ of the cases; and there is a low signal $g^{\mathrm{a}}\left(\AA_{i_{1}} ; ; \mathrm{i}\right.$ ) that with probability $p(0)$ leads to reelect an incompetent in $(1 ; s)(1 ; r)$ of the cases. Expected utility in period $t+1$ if there are no elections is based on the probabilities $(r ; 1 ; r)$ that incumbent is competent or not. Doing the algebra, the expected utility next period of the electoral option of reelecting the incumbent is positive because of the higher probability of replacing incumbents with below average competency: $(1 ; r) r f E\left[u_{t+1}^{a} j\right.$

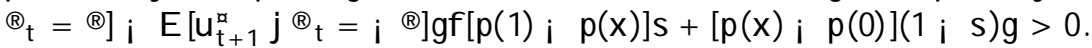




\section{Conceptual Framework}

We now brieły review some of the conceptual aspects underlying the model.

\section{A. A symmetric Information on Opportunism}

Heterogeneity along the dimensions of competency and character is quite widespread. For instance, Covey et al. (1995, pp. 240-1) focus on the importance of both competency and character for business organizations. They also give more homely examples, such as wanting physicians to be competent, to give us the right treatment, and honest, to not prescribe a costly treatment we do not nœd. The issue of heterogeneity in honesty has been already explored, among other areas, in the literature on corruption (e.g. Weinschelbaum, 1998) and governance (e.g. Dixit, 2001).

The assumption about asymmetric information on opportunism springs naturally from the fact that opportunism characterizes preferences. Preferences are subjective. As argued at the beginning of the paper, opportunism is not directly observable. One has to infer an individual's character from the actions the individual takes. A ctions reveal preferences.

\section{B. Signaling in Spence}

The present signaling model is a variation of Spence (1973). The principals here are voters, rather than ..rms. The agents are politicians, rather than workers. The signal is given by visible budget items, rather than by 
education.

Riley (2001) considers an extension of the original Spence model from two types of agents to four types of agents. This resembles our two-dimensional asymmetric information framework, where there also are four types of agents: competent and incompetent incumbents, which can be opportunistic or not.

However, the results of our two-dimensional asymmetric information framework dixer sharply from Riley's analysis of Spence. R iley considers the exect of "noise". He shows that the separating equilibrium of the Spence signaling model breaks down if some unproductive workers have low signaling costs (in terms of years of formal education), while some productive workers have high signaling costs. He shows that, in that case, no obvious alternative equilibrium exists. Unlike the Riley model, here there is a sharply de..ned partially pooling equilibrium. The reason is that the signaling costs of the four types of agents dixer.

If one were to apply the present framework to the case of labor markets, it would roughly run as follows. The dixerences in character imply that the taste for study, or perhaps the desire to achieve social recognition, can vary (in our discrete example, they would be either high or low). This trait is independent from the fact that highly competent individuals have lower costs of completing formal education. A $n$ application of this framework to the Spence signaling model, in the presence of high heterogeneity in character, will lead to a partially pooling equilibrium where very competent individuals who are highly motivated will stand out from the rest. At the other extreme, 
there will be types with low competence and low motivation. In the middle, the mix of competent individuals, and of hard-driven individuals that want to succeed, would be diф cult to tell apart. Extreme types would still send unequivocal signals.

\section{Low Visibility as Discretion}

In the paper, the incumbent can successfully manipulate the budget because of the fact that some budget items are not visible before elections.

A possible interpretation of low visibility is as a measure of the discretionary power vested in the executive branch. Decisions that need the authorization of congress can be expected to be much more visible than decisions that can be solely decided by the executive power. If low visibility is a measure of the discretion enjoyed by the executive in unilaterally deciding .scal policy, a variable ${ }^{\circledR 2}(0 ; 1]$ can be used as an index for the degree of discretion:

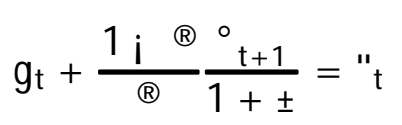

In the paper, we assumed that less visible item ${ }^{\circ} \mathrm{t}+1$ fell by $1+ \pm$ when visible items $g_{t}$ increase by one unit, which would correspond to $\AA=1=2$. As $\circledast$ approaches one, on the other hand, all budget items tend to become visible, so $d^{\circ}{ }_{t+1}=d g_{t}=i\left[{ }^{\circledR}=(1 ; B)\right](1+\#$ tends to minus in.. nity, and the costs of producing budget cycles explode. One way to mitigate cycles could 
therefore be to reduce the discretion of the executive. ${ }^{11}$

The degree of discretion depends on the institutional framework. The discretion of the U.S. president is small and subject to a large control of congress, when compared to the parliamentary system in E urope where the executive has quasi-legislative powers (cf. Carey and Shugart, 1998).

The dixerences in thediscretion that the executive enjoys can hel p explain why A lesina, Roubini, and Cohen (1997, chaps. 4 and 6), observe there is no recent evidence of opportunistic cycles in the U.S., specially after 1980 when many federal transfer programs in the U.S. have become mandatory by acts of Congress so they cannot be easily manipulated for short run purposes. In contrast, opportunistic cycles are present in other OECD countries.

Latin A merica stands in even starker contrast to the U.S. experience. Latin America followed the lead pioneered by the U.S. of a division of powers à la M ontesquieu, but in practice there has been a concentration of quasilegislative powers in the hands of the president. The degree of executive discretion is substantial (Carey and Shugart, 1998). Since the study by A mes (1987), there is also ample evidence of budget cycles in Latin America.

M ore generally, budget cycles are especially strong among developing countries (Drazen, 2001). These dixerences in outcomes may rełect differences in institutional structures of the type outlined here.

\footnotetext{
${ }^{11}$ A nother is to impose term limits. However, term limits that rule out reelection not only eliminate cycles, they also eliminate the electoral option of reelecting a competent incumbent.
} 


\section{A dverse Selection in Politics}

It is sometimes said that the worst, least scrupulous people are selected by the political process. However, the issue of lemons in politics, like lemons in markets, can be expected to depend on the institutional structure.

In the speci...c case of R PBC, if one interprets low visibility as high discretionality, more opportunistic incumbents increase their chances of political survival when the executive is given a lot of short-run leeway on budgetary matters. This is detrimental because it leads to reward the wrong type of incumbents. If there were no room for cycles, voters would be able to tell competent and incompetent incumbents perfectly apart, contrary to what happens in the partially pooling equilibrium of P roposition 2.

Political history often seems to be a long succession of dominance by the most ruthless individuals. For instance, the assassinations carried out by feudal lords and princes in Europe to impose their power, or contemporary rulers like Sadam Hussein, who distinguished himself by his violent character, working his way up to head the secret police in I rak before staging a coup that put him in power. These cases of adverse political selection would almost certainly not have not made it to the top in a system with more restrictive rul es such as the U.S., or, for that matter, in most any of today's constitutional democracies.

The Federalist notes that we are governed by men, not angels, so we must design political institutions taking that into account. This paper marks the dixerences among politicians. One has to insure against the worst possible 
cases. Institutions can in fact determine which types are most successful in the political arena. ${ }^{12}$

\section{IV . Conclusions}

Previous literature on RPBC implicitly assumes that voters know the incumbent's exact degree of opportunism, so as to ..gure out just how far the incumbent is willing to go to get reelected. This paper considers a more general setup where there is heterogeneity and asymmetric information on opportunism.

In the R ogox vein, we model the political cycle in terms of ..scal policy. ${ }^{13}$ This paper considers only two types of competency and of opportunism. With high heterogeneity in opportunism, two-dimensional asymmetric information destroys the separating equilibrium characteristic of earlier models. In its place, there is a partially pooling equilibrium where cycles are caused by highly opportunistic incumbents, regardless of their competence. T he welfare implications of RPBC are less favorable because the informativeness of cycles is reduced.

Empirically, there is a criterion to distinguish whether cycles lead or not to a separating equilibrium. The observational dixerence is that in a par-

\footnotetext{
${ }^{12}$ Caselli and Morelli (2001) endogeneize the entry into politics, studying precisely the issue of what determines the mix of competency and honesty of elected o $\not$ cials.

$13 T$ he story in terms of active monetary policy would be quite similar. However, Drazen (2001) analyzes how explaining political cycles as the result of monetary surprises rather than budget cycles is less convincing both theoretically and empirically.
} 
tially pooling equilibrium voters can be surprised after elections, while in a separating equilibrium they always foresee the correct level of competency. Though indeed voters are apt to be disappointed by whom they voted, the reason for developing this extended setup is theoretical: the fact that the incumbent's preferences, the springs and wells of action, are not directly observed by voters.

This signaling model implies a variant of Spence (1973). Though the equilibrium is no longer separating, signaling is resilient to theintroduction of asymmetric information in two dimensions. In the middle ground it is diф cult to tell dixerent types apart, but going to extremes leads to single oneself out. The probability of high competency is thus monotonically increasing in the signal.

The distinction between visible and non-visible budget items that is at the root of the budget cycle can be related to the degree of discretion enjoyed by the executive. In this sense, the U.S. Congress stands out for having substantially curbed the discretion of the President, which may help explain why the impact of opportunistic cycles seems to have disappeared in recent years. The institutional structure can be specially important to determine to what extent lemons populate the political arena. 


\section{R eferences}

[1] A kerlof, George. "The market for 'Lemons': Quality uncertainty and the market mechanism." Quarterly J ournal of E conomics, August 1970, 84(3), pp. 488-500.

[2] A lesina, Alberto; Roubini, Nouriel and Cohen, Gerald. Political Cycles and the Macroeconomy. Cambridge: MIT Press, 1997.

[3] A mes, Barry. Political Survival. Politicians and Public Policy in Latin America. B erkeley: University of California P ress, 1987.

[4] Carey, J ohn M. and Shugart, Matthew S., eds. Executive Decree Authority. Cambridge: Cambridge University Press, 1998.

[5] Caselli, Francesco, and Morelli, Massimo. "Bad politicians." Working Paper, NBER, October 2001.

[6] Covey, Stephen; Merill, Roger and M erill, Rebecca. F irst Things F irst. N ew York: Simon and Schuster, 1995.

[7] Dixit, Avinash. "On models of economic governance." Presidential Address to the Econometric Society Meetings (http:// www.princeton. edu/ dixitak/ home/ govmodes. pdf), 2001.

[8] Downs, Anthony. An Economic Theory of Democracy. New York: Harper and R ow, 1957. 
[9] Drazen, Allan. "The political business cycle after 25 years." NBER Macroeconomics Annual. Forthcoming, 2001.

[10] Lohmann, Susanne. "Rationalizing the political business cycle: A workhorse model." Economics and Politics, March 1998, 10(1), pp. 1-17.

[11] N ordhaus, William. "The political business cycle." Review of Economic Studies, A pril 1975, 42(2), pp. 169-90.

[12] Persson, Torsten, and Guido Tabellini. Macroeconomic Policy, Credibility and Politics. Chur: Harwood A cademic Publishers, 1990.

[13] Persson, Torsten, and Guido Tabellini. "P ol itical economics and macroeconomic policy," in J ohn B. Taylor and Michael Woodford, eds., Handbook of Macroeconomics, 1C. A msterdam: North Holland, 1999.

[14] Riley, J ohn. "Silver signals: 25 years of signaling and screening." J ournal of E conomic Literature, J une 2001, 39(2), pp. 432-78.

[15] Rogox, K enneth. "Equilibrium political budget cycles." American E conomic Review, March 1990, 80(1), pp. 21-36.

[16] Rogox, Kenneth and Sibert, Anne. "E lections and macroeconomic policy cycles." Review of Economic Studies, J anuary 1988, 55(1), pp. 1-16.

[17] Schumpeter, J oseph A. Capitalism, Socialism and Democracy. New York: Harper \& Brothers, 1942. 
[18] Spence, Michael. "J ob market signaling." Quarterly J ournal of Economics, A ugust 1973, 87(3), pp. 355-379.

[19] Stein, Ernesto and Streb, J orge. "Elections and the timing of devaluations." Working paper, Universidad del CEM A, 1999.

[20] Tufte, Edward. P olitical C ontrol of the E conomy. P rinceton: Princeton U niversity Press, 1978.

[21] Weinschelbaum, Federico. The Triangle of Corruption. Ph.D. dissertation, UCLA, 1998. 


\section{Timing with asymmetric information on competency}

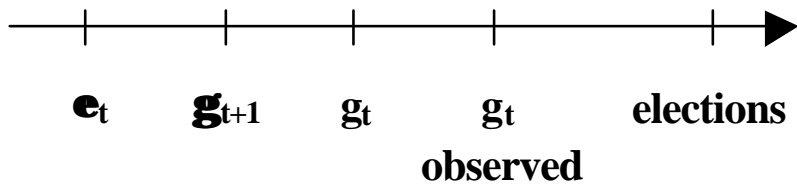

Figure 1:

Deviations from Pooling Equilibrium $g_{t}\left(\alpha_{t-1}, \alpha\right)$

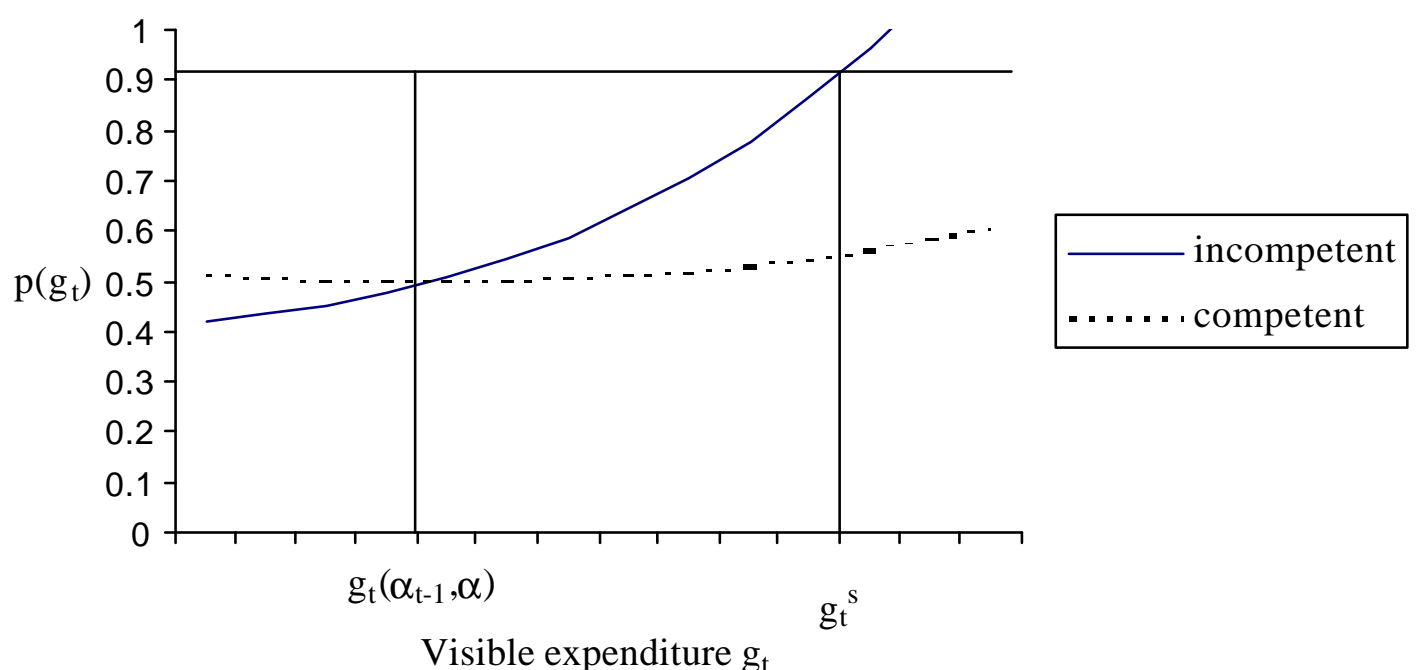

Figure 2: 
Deviations from Partially Pooling Equilibrium gt ${ }_{t}^{*}\left(\alpha_{t-1}, \alpha\right)$

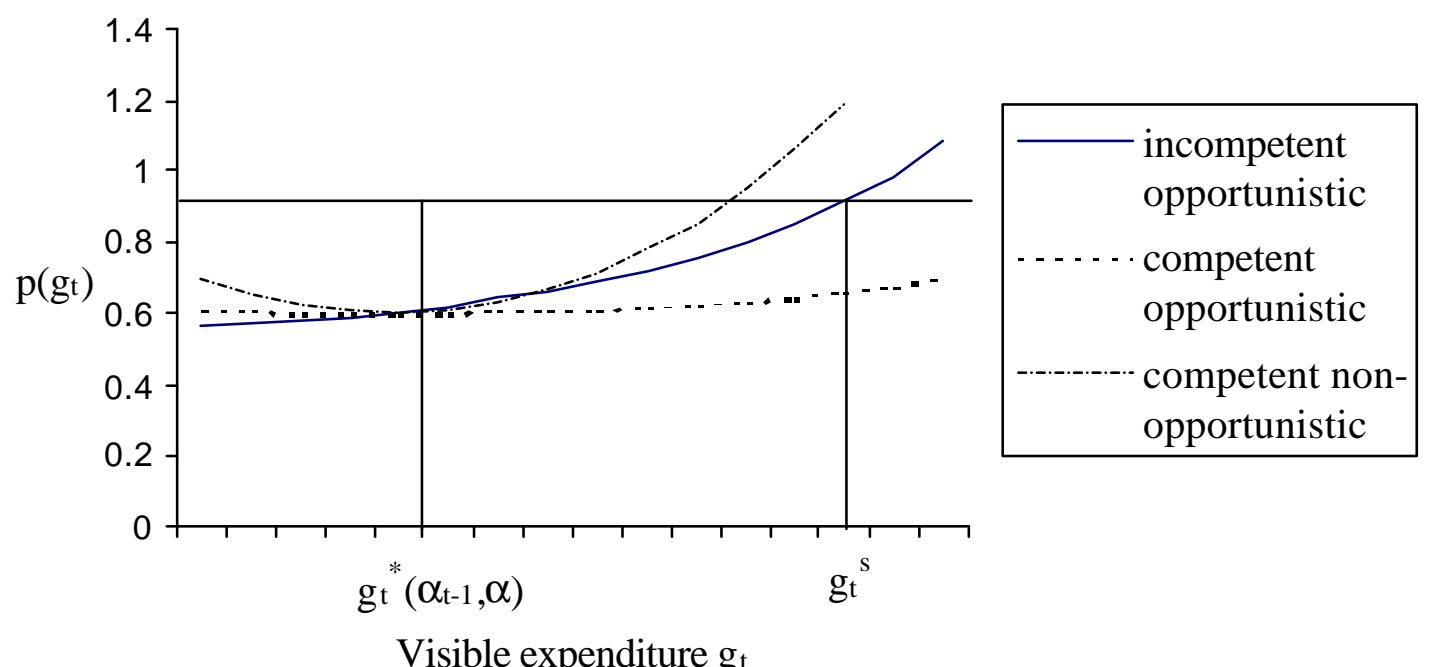

Figure 3: 